\title{
Coastal cities: a discussion of the flooding potential of coastal cities in this century
}

\author{
O. T. Gudmestad \\ Department of Mechanical and Structural Engineering \\ and Material Science, University of Stavanger, Norway
}

\begin{abstract}
There are several causes for occasionally increased water levels in major cities. Such incidents are normally associated with large storm situations. The consequences could be huge damage, public disarray and the loss of many lives.

Further details of the situations are discussed with an emphasis on:

- the sinking caused by ground water extraction;

- the effect of rising sea levels;

- climatological changes caused by global warming leading to intense low pressures and frequent high waves;

- extreme storm surges, combined with high tides, leading to an increase in the average water level, which, combined with large waves, will overtop most present dikes.

The discussion is focused on remedial measures to sustain the inflow of water and limit accidental and economic damage. Emphasis is put on:

- safeguarding critical infrastructure with the building of local protection barriers against inflow of water to metros, for protection of vulnerable buildings and for forced blocking of dangerous situations on roads and railways;

- evaluating the effect of beach erosion on critical infrastructure, including buildings, with an assessment of strengthening strategy and the use of plants to limit erosion;

- the need for preparation of dikes to protect cities or parts of these from high water effect;

- the efficiency of floating protection barriers to reduce the effect of waves while accepting the increase in high tide and storm surge effects;

- discussing the safety level obtainable with realistic funding.
\end{abstract}


We do, however, also point to the fact that flooding has occurred in the past and that we shall expect damaging flooding in the future, regardless of the measures taken to protect assets against such situations. Then, the authorities are left with few alternatives but the evacuation of the population and acceptance of the infrastructure damage. A strategy of limiting the consequences of flooding might be more successful in the future compared to limiting the flooding situations.

Keywords: storm surges, sea level rise, flooding, protection barriers, dikes.

\section{Introduction}

The growing concern for the safety of coastal cities, in regard to flooding and damage caused by high water, waves and the spread of pollution, should be met with discussions related to the identification of the threat and by mitigating measures. This involves safety for the inhabitants of the cities, the long-term consequences of pollution and the loss of assets, including the loss of business during the damage period and prior to full rebuilding.

It became clear recently that many cities are very prone to huge damage when the New York area was flooded on $29^{\text {th }}$ October 2012 (hurricane Sandy); this was caused by a storm surge of $13 \mathrm{ft}$. In addition, waves caused considerable damage along the coastline. Seven New York subway tunnels and road tunnels were partly flooded, giving rise to damage of the infrastructure system. It was also reported that rats came to the surface during the flooding, potentially causing an epidemic situation.

Engineers will seek measures to mitigate such damage, concentrating on those solutions with the highest cost benefit for invested funds, after having taken action to save as many lives as possible during flooding situations.

It could be claimed that the present increase in average temperature worldwide will give rise to more situations involving severe flooding; however, severe flooding has also occurred in the past (Lamb [1] and Bird [2]). Nevertheless, the problem has increased as the infrastructures of modern cities are becoming more and more complex. In addition, some cities (for example Venice) have made themselves more vulnerable by lowering the groundwater causing ground settlements.

It is obvious that storm surges (often in combination with high tides) will cause the sea level to rise by several meters in the case of very strong winds blowing in a certain direction. This has been the nightmare for low-level regions and cities; most well-known are the occasional flooding of the Netherlands, Bangladesh and more recently Venice and the Louisiana coast. Storm barriers have been built in the richest countries to protect regions and cities, while the poorer areas have been left to themselves. The question arises as to whether successful coastal cities of the future will all be placed behind dikes, while poorer urban areas will be left to dramatic flooding situations.

In this respect, the effects of waves also vary as, in addition to the storm surges and high tide, they could overtop dikes and cause considerable damage. 
Where protection has been built, it is also of concern that storm situations seem to occur more frequently and with higher water levels than statistics should predict. This effect is a consequence of global warming, and is well documented by scientists. Therefore, in order to maintain a high safety level, the dikes have to be built higher and higher, requiring considerable additional funding, taking money from other important investments that the society would prioritize.

In this paper, we will discuss the past and present situations and examine solutions that could be prioritized as regions and cities must live with the consequences of future severe rises in sea water level. Of particular importance is the willingness to accept occasional flooding and the possibility for evacuation in the case of dramatic situations.

\section{Past severe flooding caused by sea level variations}

\subsection{The Southern North Sea}

The author was first alerted to the problem of storm surges and flooding during the storm in January 1953 (Figure 1). In my rural community, there was an effort to provide help to the Dutch, and the newspapers were filled with dramatic pictures of people evacuating to their roofs. More than 1800 fatalities were reported in the Netherlands with another 300 dead in Britain. The storm surge was more than $18 \mathrm{ft}$ in certain areas (Figure 2) and breached the dikes at several locations (d'Angremond [3]). In the aftermath, the dikes were strengthened and later a new barrier system, the Delta Barrier System, was designed and installed (Figure 3) to provide security during future incidents. The system keeps the water out by a system of gates that can be closed in the case of severe storm surges.

The 1953 situation was very critical; however, there have been many incidents in the past that caused huge flooding of the Netherlands and the loss of many lives. During the night of Christmas 1717, the coastal areas of the Netherlands, Germany, and Scandinavia were hit by a severe north-western storm. An estimated 14,000 people died. This was the worst flood for four centuries.

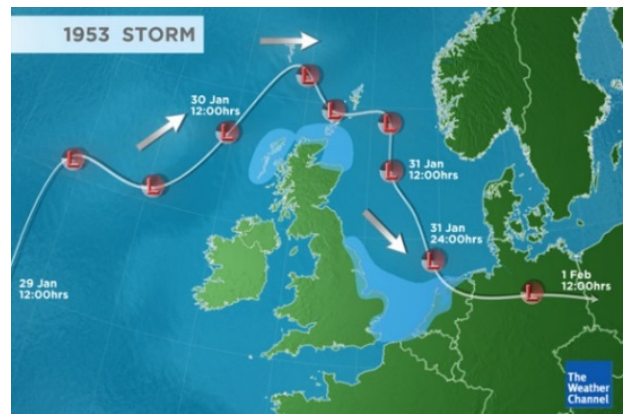

Figure 1: The path of the low pressure center during the flooding of Holland and Britain in January 1953. 


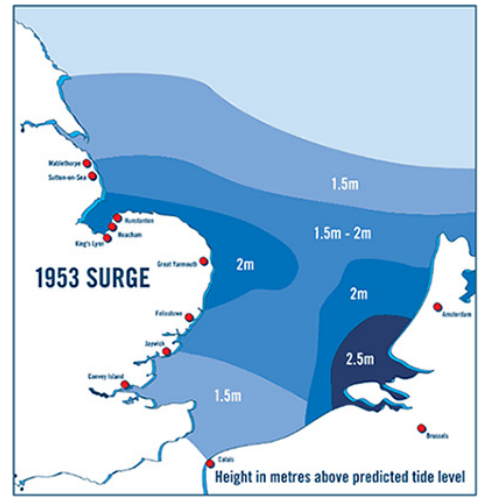

Figure 2: Modeled surge height during the flooding of 1953 (source: UK Environment Agency).

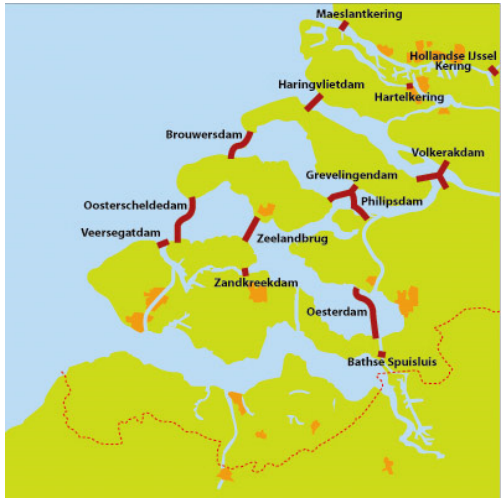

Figure 3: Barriers forming parts of the Delta Barrier System (source:

http://www.deltawerken. com/Deltaworks/23.html).

\subsection{Bangladesh}

Bangladesh is particularly susceptible to flooding; a one-meter rise in sea level would inundate $30,000 \mathrm{~km}^{2}$ and displace 20 million people (Figure 4).

The country is prone to both river flooding when there is much rain in the Himalayas and flooding due to storm surges (Penn State [4]). In the past huge catastrophes have occurred; recently the worst flooding occurred on 10th November 1970 and on 30th April 1991. These caused the loss of 300,000 and 130,000 human lives respectively (WMO [5]).

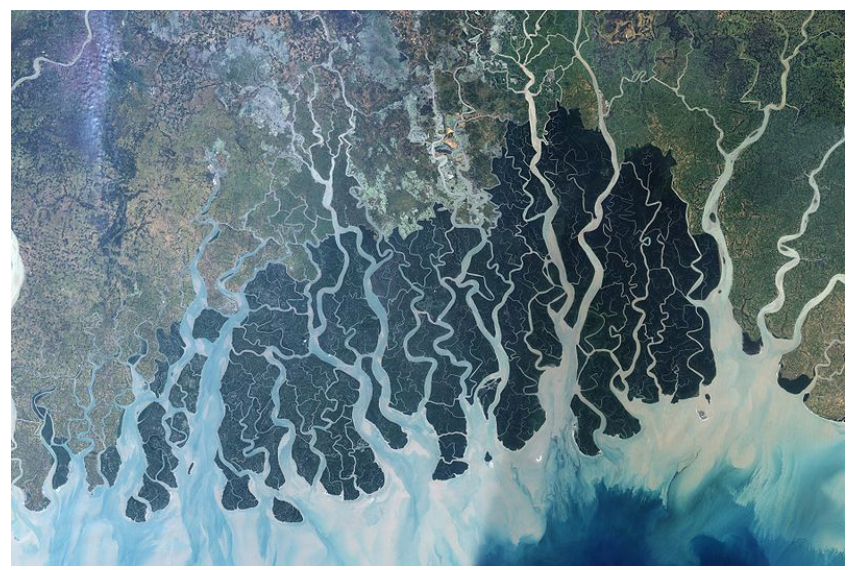

Figure 4: Parts of Bangladesh that will be below sea water level in the case of $1 \mathrm{~m}$ sea level rise [4]. 


\section{Present status in some areas with respect to flooding potential}

\subsection{The Netherlands}

The present status with respect to the flooding of parts of the Netherlands is summarized by Climate Adaption [6]. Of particular concern and uncertainty is the potential sea level rise over the coming decades. The Dutch have recognized that it will not be possible to build the dikes so high that the risk to personnel in the case of severe situations will be eliminated. Some, e.g. Brouwer and Wellinga [7], argue, however, that the risk is too high and the debate is ongoing regarding the amount of funding that should be spent on flood protection. Figure 5 shows the risk level adopted in the Netherlands in the case of flooding as compared to other risks. Even when taking the high uncertainty into account, indicated as a band in the graph, flood risks are well above external safety risks. The probability of large numbers of casualties is much greater with floods than with all the external safety risks put together, as discussed in a report prepared by the Dutch authorities [8]; see also update by Slomp [9].

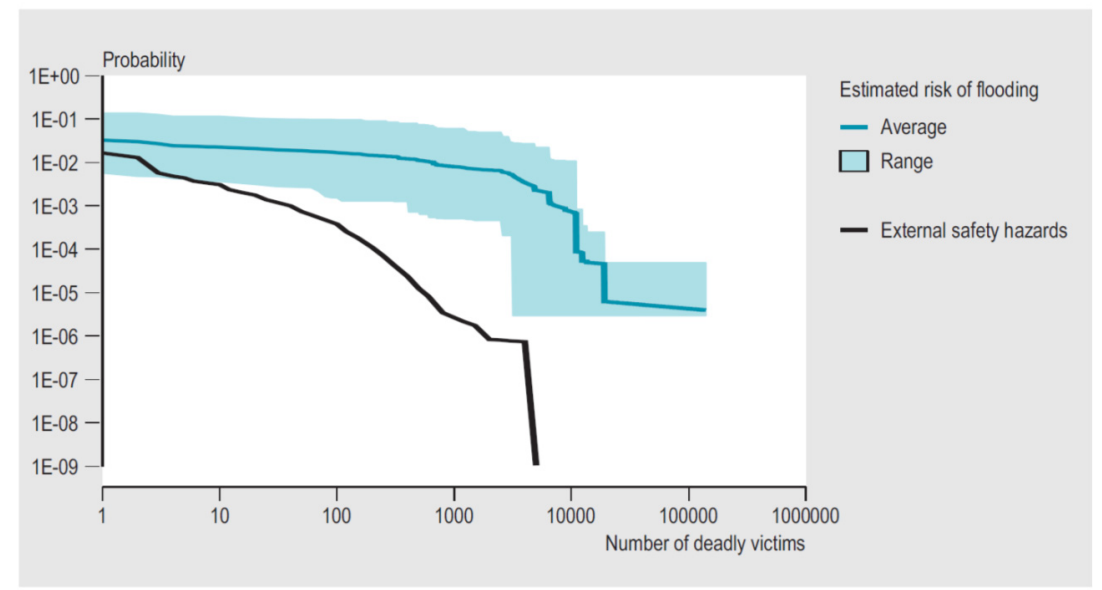

Figure 5: Risk of fatalities due to flooding in the Netherlands as compared to other risks (Dutch Authorities [8]).

\subsection{London area}

Figure 6 shows the potential damage loss along the Thames Estuary in the case of a 2000-year event flooding (annual probability of $5 \times 10^{-4}$ ). These considerations have led to the construction of the Thames Barrier. The Barrier will prevent Greater London from being flooded by exceptionally high tides and storm surges. The Barrier is closed during high tide, and at low tide it can be opened to restore the flow. 


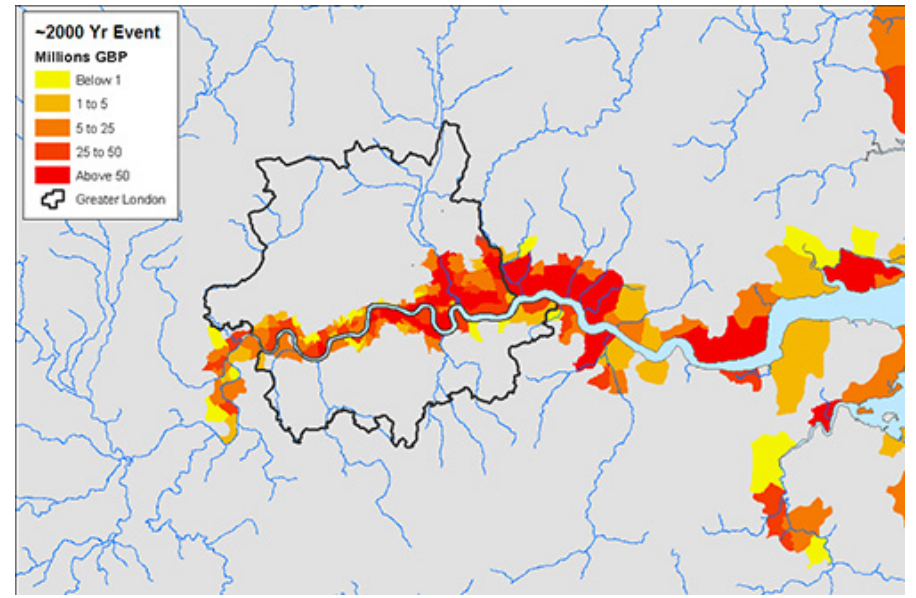

Figure 6: Flood damage costs in the case of 2000-yr flooding of Greater London.

\subsection{Low islands in the Pacific}

Some small island nations in the western Pacific are very vulnerable to sea level rise as they are very low. These islands include Kiribati, Tuvalu and the Marshall Islands, Penn State [4]. The possible sea level rise to the year 2050 could cause these nations to completely disappear, and an approximate 100,000 inhabitants from Kiribati alone may need to relocate over the coming three decades.

\section{Remedial measures to avoid the effects of extensive flooding}

The engineering society has for centuries worked to protect land and cities from the threat of flooding. It could well be claimed that the Dutch have been leaders in engineering ingenuity and determination. Huge dike projects have been undertaken leading eventually to the construction of barriers to protect the most vulnerable areas. Similar barrier projects have been undertaken in England (the Thames Barrier) and in Italy, where Venice has been protected by the construction of a Mobile Barrier System (MOSE) (see Figure 7, Stimpson [10]). The situation for Venice is particularly critical as the city is both a world heritage site and it sank $12 \mathrm{~cm}$ from 1940 to 1970 due to extraction and lowering of the groundwater level.

It will, however, not be possible to hide all major cities behind dikes. Analysis such as that carried out in the Netherlands (Slomp [9]), will be necessary to evaluate whether the safety of the protection system is sufficient.

Furthermore, emphasis will have to be placed on living with flooding and saving lives and assets during flood situations.

There are many engineering solutions that will be considered to minimize the effects of high sea water levels, in addition to the preparation of dikes and large barrier systems. These include, but are not limited to, local barriers to protect the most critical infrastructure like tunnels and metros and raising the entrance to 
buildings to avoid water ingress. Future buildings may have a ground floor that can tolerate flooding, and building houses on floats that will lift with the water level could also be considered. During situations involving large tides and storm surges, the effects of the waves on coastal structures are particularly challenging. Planting will limit the potential coastal erosion during these situations; however, the waves will easily ride over any protection. Installing floating wave breakers to protect particularly vulnerable areas against wave overtopping could, therefore, be considered.

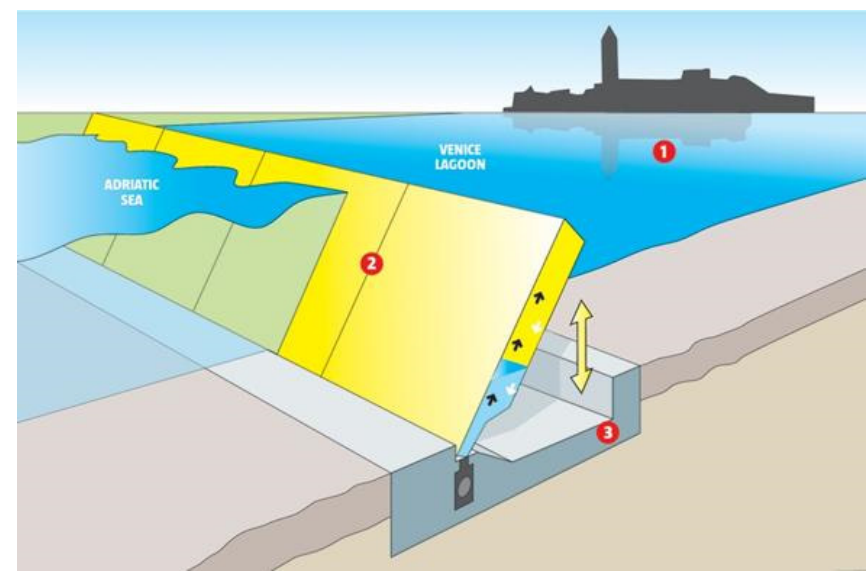

Figure 7: The Mobile Barrier System (MOSE) in the Venice Lagoon (Stimpson [9]).

In order to reduce the loss of lives in the case of extensive flooding, accurate weather forecasting is needed along with mass evacuation in the case of the most critical situations. The need for vessels to ensure evacuation could be reinforced, as families and work places could be required to keep evacuation vessels available in the most critical areas.

A report from NRC [11], calls for consequence-reducing measures. This approach will be more important in the future with the potential for larger storms, higher storm surges and more frequent flood situations.

\section{Conclusions and recommendations}

In the preceding sections, we have discussed past and present extensive flooding of large regions and in particular of large cities. Remedial measures to avoid extensive flooding are considered. The situation is critical as general global warming is causing a sea water level rise. In addition, more intense storms occur more frequently, causing increased storm surge levels and larger waves approaching coastal regions.

It must be realized that large funding is required to cope with the situation, although it will not be possible to hide all urban regions behind expensive dikes. 
The societies will have to accept more recurring flooding and will have to put an emphasis on the evacuation of personnel, limitation of damage by securing the most important and costly infrastructure, and planning for the transfer of important functions to higher ground. The relocation of people is also foreseen. Placing all major cities behind dikes is a very unlikely situation for the later decades of this century.

Engineering ingenuity is most welcome to identify cost-efficient means to mitigate the effects, i.e. to reduce the consequences of future flood situations.

\section{References}

[1] Lamb, H. H., 1997, Climate, History and the Modern World, Routledge, Oxford, England.

[2] Bird, E.C.F., 1993, Submerging Coasts, The Effects of a Rising Sea Level on Coastal Environments, J. Wiley Sons, Chester, England.

[3] d'Angremond, K., 2003, "From Disaster to Delta Project: The Storm Flood of 1953", Terra et Aqua - Number 90 - March 2003. See also: https://www.iadc-dredging.com/ul/cms/terraetaqua/document/1/2/4/124/ 124/1/terra-et-aqua-nr90-01.pdf

[4] Penn State, College of Earth and Mineral Science, 2014, "The Future of Sea Level Rise: The Role of Coastal Engineering”, https:/www.eeducation.psu.edu/earth103/node/754

[5] World Meteorological Organization, WMO, 2003, "Integrated Flood Management Case Study Bangladesh: Flood Management", https://cleancookstoves.org/binary-data/RESOURCE/file/000/000/78$1 . p d f$

[6] http:/www.climateadaptation.eu/netherlands/coastal-floods/

[7] Bouwer, L. M. and Vellinga, P. (2007), On the flood risk in the Netherlands, Chapter 24 in S. Begum et al. (eds.), Flood Risk Management in Europe, pp. 469-484, Springer, the Netherlands.

[8] Netherlands Environmental Assessment Agency, National Institute for Public Health and the Environment (RIVM), 2004, "Dutch dikes, and risk hikes, a thematic policy evaluation of risks of flooding in the Netherlands"

[9] Slomp, R., 2012, "Flood Risk and Water Management in the Netherlands", A 2012 update. Rijkswaterstaat, the Netherlands. http://united kingdom.nlembassy.org/binaries/content/assets/postenweb/v/verenigd_kon inkrijk_van_groot_brittannie_en_noord_ierland/nederlandse-ambassadein-londen/import/key-topics/flood-risk-and-water-management-in-thenetherlands-a-2012-update1.pdf

[10] Stimpson, J., 2010, "Barrier at milestone", New Civil Engineer, http://www.nce.co.uk/news/international/barrier-at-milestone/8602531. $\underline{\text { article }}$

[11] National Research Council of the National Academies, 2001, Reducing Coastal Risk on the East and Gulf Coasts. Committee on U.S. Army Corps of Engineers Water Resources Science, Engineering, and Planning: Coastal Risk Reduction, Water Science and Technology Board, Ocean Studies 
Board Division on Earth and Life Studies, The National Academic press, Washington D.C., http://www.floods.org/ace-files/documentlibrary/committees/Coastal/ Reducing_Coastal_Risk_on_the_East_and_Gulf_Coasts_NAS-2014.pdf 